\title{
Reproducibility of essential elements chromium, manganese, iron, zinc and selenium in spot samples, first-morning voids and 24-h collections from healthy adult men
}

\author{
Heng-Gui Chen, Ying-Jun Chen, Chen Chen, Zhou-Zheng Tu, Qi Lu, Ping Wu, \\ Jun-Xiang Chen, Yi-Xin Wang*十 and An Pan*† \\ Department of Epidemiology and Biostatistics, and Ministry of Education Key Laboratory of Environment and Health, and State \\ Key Laboratory of Environmental Health (Incubating), School of Public Health, Tongii Medical College, Huazhong University of \\ Science and Technology, Wuban, Hubei Province, People's Republic of China
}

(Submitted 11 February 2019 - Final revision received 29 April 2019 - Accepted 1 May 2019; First published online 24 July 2019)

\begin{abstract}
Evaluation of $\mathrm{Cr}, \mathrm{Mn}, \mathrm{Fe}, \mathrm{Zn}$ and Se in humans is challenged by the potentially high within-individual variability of these elements in biological specimens, which are poorly characterised. This study aimed to evaluate their within-day, between-day and between-month variability in spot samples, first-morning voids and 24-h collections. A total of 529 spot urine samples (including eighty-eight first-morning voids and 24-h collections) were collected from eleven Chinese adult men on days $0,1,2,3,4,30,60$ and 90 and analysed for these five elements using inductively coupled plasma-MS. Intraclass correlation coefficients (ICC) were utilised to characterise the reproducibility, and their sensitivity and specificity were analysed to assess how well a single measurement classified individuals' 3-month average exposures. Serial measurements of Zn in spot samples exhibited fair to good reproducibility (creatinine-adjusted ICC $=0.47$ ) over five consecutive days, which became poor when the samples were gathered months apart (creatinine-adjusted ICC $=0.33$ ). The reproducibility of $\mathrm{Cr}, \mathrm{Mn}, \mathrm{Fe}$ and Se in spot samples was poor over periods ranging from days to months (creatinine-adjusted ICC $=0 \cdot 01-0 \cdot 12$ ). Two spot samples were sufficient for classifying $60 \%$ of the men who truly had the highest (top 33 \%) 3-month average Zn concentrations; for Cr, Mn, Fe and Se, however, at least three specimens were required to achieve similar sensitivities. In conclusion, urinary $\mathrm{Cr}, \mathrm{Mn}, \mathrm{Fe}, \mathrm{Zn}$ and Se concentrations showed a strong within-individual variability, and a single measurement is not enough to efficiently characterise individuals' long-term exposures.
\end{abstract}

Key words: Essential elements: Urine samples: Reproducibility: Variability: Misclassification

$\mathrm{Mn}, \mathrm{Fe}, \mathrm{Zn}$ and Se are well-known essential elements that act as cofactors for a variety of important proteins and enzymes ${ }^{(1)}$. Many toxicological and human evidence have revealed that a deficiency of these elements was associated with many chronic diseases (e.g. CVD, diabetes and chronic liver disease) $)^{(2-5)}$. However, excessive exposure to these elements, either voluntarily via supplementation or involuntarily via intake of contaminated food and water, has also been linked to increased risks of diabetes $^{(4)}$, the metabolic syndrome ${ }^{(6)}$ kidney $^{(7)}$ and gut diseases $^{(8)}$, and cancer ${ }^{(9)}$. Cr is also postulated to be involved in regulating the metabolism of carbohydrates and lipids by enhancing insulin's efficacy ${ }^{(10)}$, though the European Food Safety Authority found no convincing evidence that $\mathrm{Cr}$ is an essential element ${ }^{(11)}$.

The collection of spot samples is non-invasive and convenient to implement ${ }^{(12,13)}$. Therefore, many epidemiological studies, especially large-scale biomonitoring investigations, such as the Canadian Health Measures Survey (CHMS) ${ }^{(14)}$, the German Environmental Specimen Bank (ESB) ${ }^{(15)}$ and the French National Nutrition and Health Survey (ENNS) ${ }^{(16)}$, all have utilised single spot urine sample to determine individuals' exposure status of $\mathrm{Cr}, \mathrm{Mn}, \mathrm{Fe}, \mathrm{Zn}$ and Se. However, the concentrations of these elements in spot samples may vary greatly over time due to the variation in external exposure (driven by the changing lifestyle or dietary habits) ${ }^{(17,18)}$ and urinary excretion rate (UER) (driven by changing salt intake and physiological status) ${ }^{(19)}$. Using creatinine to adjust for urine dilution may also introduce variation that does not reflect urine dilution ${ }^{(20)}$.

Very few studies to date have explored the reproducibility of urinary concentrations of $\mathrm{Cr}, \mathrm{Mn}, \mathrm{Fe}, \mathrm{Zn}$ and Se. In a study conducted in the USA, Gargas et al. ${ }^{(21)}$ found that Cr concentrations in spot urine samples varied by orders of magnitude in ten

Abbreviations: ICC, intraclass correlation coefficient; UER, urinary excretion rate.

* Corresponding authors: A. Pan, email panan@hust.edu.cn; Y.-X. Wang, email wangyx0203@163.com

$\dagger$ Authors contributed equally. 
volunteers. In a Belgium study, Smolders et al. ${ }^{(17)}$ reported poor reproducibility in urinary $\mathrm{Mn}$ concentrations over a 6-d period in four couples (creatinine-adjusted intraclass correlation coefficient $($ ICC $)=0 \cdot 28)$. In an Italy study, Paglia et al. ${ }^{(22)}$ found high seasonal variations in $\mathrm{Mn}, \mathrm{Zn}$ and Se in first-morning voids (all ICC $<0.50)$ in seven healthy volunteers. However, no studies have comprehensively assessed the within-day, between-day and between-month variability of $\mathrm{Cr}, \mathrm{Mn}, \mathrm{Fe}, \mathrm{Zn}$ and Se concentrations in different sample types (e.g. spot samples, firstmorning voids or 24-h collections). The impact of different concentration correction methods (i.e. creatinine adjustment, creatinine as a covariate and UER) on the reproducibility of these elements in urine was also unclear.

To fill the data gap in this study, we characterised the withinday, between-day and between-month variability of serial measurements of $\mathrm{Cr}, \mathrm{Mn}, \mathrm{Fe}, \mathrm{Zn}$ and Se in spot samples, first-morning voids and 24-h collections from eleven Chinese adult men, using different correction models. Additionally, we mimicked the exposure classification process in epidemiological studies to calculate the sensitivity and specificity for classifying individuals' high (top 33\%) 3-month average exposures with single or repeated specimens.

\section{Methods}

\section{Study population}

From 22 October 2012 to 21 January 2013, eleven healthy adult men were recruited to participate in the study designed to explore the variability in urinary heavy metals and haloacetic acids ${ }^{(18,23)}$. Their basic demographics have been shown in our previous study ${ }^{(18)}$. To reduce the uncertainty related to demographic characteristic and lifestyle factors that may contribute to the variability in urinary element concentrations, we included only volunteers who were non-smokers and did not have any occupational exposure to metals. Their age and BMI ranged from 21 to 28 years (mean: $23.64 \pm 1.96$ ) and 18.5 to $25.1 \mathrm{~kg} / \mathrm{m}^{2}$ (mean: $21.67 \pm 2 \cdot 13$ ), respectively. On average, participants urinated six times per d (range: 3-11 times), and the volume of spot samples was $195 \mathrm{ml}$ (range: 20-741 ml). Participants had no restriction on their daily dietary intake but were requested to record the types of food consumed throughout the eight sampling days. Three men reported eating fish only once in the eight sampling days during the 3-month sampling period, and none of the participants took dietary supplementation or ate seafood other than fish on the sampling days. This study was conducted according to the guidelines laid down in the Declaration of Helsinki and approved by the Ethics Committee of Tongji Medical College. All participants signed informed consent forms before participation.

\section{Urine sample collection}

During the 3-month sampling period, all spot samples were collected from the eleven adult men on days $0,1,2,3$ and 4 (days apart) and on days 30, 60 and 90 (including day 0, months apart). To reduce the effect of changing dietary patterns on the weekend $^{(24)}$, all the samples were collected on weekdays. Detailed sampling procedure has been described in our prior publications ${ }^{(18,23)}$. Briefly, participants were asked to collect all their spot samples in element-free plastic containers throughout the sampling days. Research staff recorded the total volume and collection time of each void, decanted the samples into a trace element-free polyethylene cup and then stored at $-40^{\circ} \mathrm{C}$ refrigerator until analysis. A total of 529 spot samples (six of 535 possible samples were missing) were finally gathered, including eighty-eight first-morning voids and 24-h collections.

Spot samples were defined as any individual urine void collected throughout a given day. A first-morning void was the first sample gathered from an individual starting at 05.00 hours. We reconstructed $24 \mathrm{~h}$ collections using the volume-weighted average of all voids gathered from an individual at or after 00.00 hours $^{(18,23)}$.

\section{Determination of chromium, manganese, iron, zinc and selenium}

Urinary concentrations of $\mathrm{Cr}, \mathrm{Mn}, \mathrm{Fe}, \mathrm{Zn}$ and Se were quantified using our established method ${ }^{(25,26)}$. Briefly, $3.0 \mathrm{ml}$ of urine sample was nitrified with $15 \mu \mathrm{HNO}_{3} 67 \% \mathrm{v} / \mathrm{v}$ (Optima ${ }^{\mathrm{TM}}$ grade; Fisher) at $5^{\circ} \mathrm{C}$ overnight, of which $1.0 \mathrm{ml}$ was diluted five times using $\mathrm{HNO}_{3} 1.2 \% \mathrm{v} / \mathrm{v}$ (Optima ${ }^{\mathrm{TM}}$ grade; Fisher). The target analytes were then quantified using an Agilent 7700x inductively coupled plasma-MS (ICP-MS; Agilent Technologies). Standard reference materials (SRM) (2670a and 1640a) and spiked pool urine samples were used as quality controls. Detected values of $\mathrm{Cr}, \mathrm{Mn}, \mathrm{Fe}, \mathrm{Zn}$ and Se were within the range of SRM 2670a and 1640a. The spiked recoveries of these elements ranged from $90 \%$ to $110 \%$, and the within-day and between-day variations were $<10 \%$. To control for possible contamination, a reagent blank sample (i.e. $3 \mathrm{ml}$ deionised water) was processed together with every twenty samples. Analyte values in all blank samples were lower than the limits of quantification (LOQ). When the detected concentrations in urine are below LOQ, it was substituted by $\mathrm{LOQ} /\left(2^{1 / 2}\right)$. Urinary creatinine concentrations were determined using an automated clinical chemistry analyser ${ }^{(27)}$.

\section{Statistical analyses}

All analyses were performed using Stata (version 13.1; Stata Corp) and $\mathrm{R}$ software (version 3.5.1, https://www.r-project. org/). Descriptive statistics were used to assess the normality of urinary $\mathrm{Cr}, \mathrm{Mn}, \mathrm{Fe}, \mathrm{Zn}$ and Se concentrations. Because of their skewed distribution, log-transformed values were applied for subsequent analyses.

Urinary measurements of $\mathrm{Cr}, \mathrm{Mn}, \mathrm{Fe}, \mathrm{Zn}$ and Se were expressed in the following four ways: (a) as unadjusted concentrations $(\mu \mathrm{g} / \mathrm{l})$, (b) as creatinine-adjusted concentrations $(\mu \mathrm{g} / \mathrm{g}$ creatinine) calculated by dividing the unadjusted concentrations by urinary creatinine ${ }^{(15)}$, (c) by adding creatinine as a covariate $^{(28)}$, and (d) as the UER of each element $(\mu \mathrm{g} / \mathrm{h})$, computed by dividing the total mass by the time since prior void ${ }^{(29)}$. Akaike information criterion values were used to assess the fit of the above-mentioned models (lower value indicates a better model fit)

A line chart was constructed to visually assess the withinindividual variability in $\mathrm{Cr}, \mathrm{Mn}, \mathrm{Fe}, \mathrm{Zn}$ and Se concentrations 
Table 1. Unadjusted $(\mu \mathrm{g} / \mathrm{l})$, creatinine-adjusted $(\mu \mathrm{g} / \mathrm{g}$ creatinine) and urinary excretion rate $(\mu \mathrm{g} / \mathrm{h})$ of chromium, manganese, iron, zinc and selenium concentrations in spot samples, first-morning voids and 24-h collections from eleven men* (Mean values, medians and interquartile ranges (IQR))

\begin{tabular}{|c|c|c|c|c|c|c|c|c|c|}
\hline \multirow[b]{2}{*}{ Exposures } & \multicolumn{3}{|c|}{ Spot samples ( $n$ 529) } & \multicolumn{3}{|c|}{ First-morning voids ( $n$ 88) } & \multicolumn{3}{|c|}{ 24-h collections ( $n$ 88) } \\
\hline & Mean & Median & IQR & Mean & Median & IQR & Mean & Median & IQR \\
\hline \multicolumn{10}{|l|}{ Unadjusted } \\
\hline $\mathrm{Cr}$ & 4.6 & $2 \cdot 2$ & $1.4-3.2$ & 13 & $2 \cdot 2$ & $1 \cdot 4-3 \cdot 1$ & $5 \cdot 7$ & $2 \cdot 3$ & $1.9-3 \cdot 0$ \\
\hline $\mathrm{Mn}$ & $2 \cdot 0$ & 1.4 & $0.98-1.9$ & 1.7 & 1.4 & $1 \cdot 2-1 \cdot 9$ & $2 \cdot 0$ & 1.6 & $1 \cdot 3-2 \cdot 1$ \\
\hline $\mathrm{Fe}$ & 39 & 28 & $21-41$ & 38 & 32 & $23-43$ & 39 & 33 & $26-44$ \\
\hline $\mathrm{Zn}$ & 343 & 264 & $149-451$ & 597 & 530 & $327-764$ & 349 & 296 & $227-441$ \\
\hline $\mathrm{Se}$ & $9 \cdot 3$ & $8 \cdot 1$ & $4 \cdot 7-13$ & 14 & 13 & $9 \cdot 1-17$ & $9 \cdot 0$ & $8 \cdot 3$ & $6 \cdot 1-10$ \\
\hline \multicolumn{10}{|c|}{ Creatinine-adjusted } \\
\hline $\mathrm{Cr}$ & 5.9 & $2 \cdot 3$ & $1 \cdot 4-3.4$ & 18 & 1.3 & $0.92-2 \cdot 3$ & $7 \cdot 1$ & $2 \cdot 2$ & $1 \cdot 7-3 \cdot 1$ \\
\hline $\mathrm{Mn}$ & 2.5 & 1.4 & $0.83-2.5$ & $1 \cdot 2$ & 0.95 & $0.63-1.4$ & $2 \cdot 0$ & 1.7 & $1 \cdot 2-2 \cdot 3$ \\
\hline $\mathrm{Fe}$ & 48 & 29 & $18-50$ & 27 & 20 & $14-36$ & 39 & 33 & $25-46$ \\
\hline $\mathrm{Zn}$ & 314 & 279 & 190-391 & 371 & 365 & 246-494 & 326 & 316 & $236-386$ \\
\hline $\mathrm{Se}$ & $8 \cdot 2$ & $8 \cdot 2$ & $6 \cdot 9-9 \cdot 7$ & 8.4 & $8 \cdot 4$ & $7 \cdot 3-9.9$ & $8 \cdot 3$ & 8.4 & $7 \cdot 1-9.5$ \\
\hline \multicolumn{10}{|c|}{ Urinary excretion rate } \\
\hline $\mathrm{Cr}$ & 0.29 & 0.11 & $0.068-0.18$ & 0.80 & 0.057 & $0.038-0.091$ & 0.38 & 0.11 & $0.081-0.15$ \\
\hline $\mathrm{Mn}$ & 0.13 & 0.072 & $0.040-0.14$ & 0.057 & 0.039 & $0.026-0.073$ & 0.099 & 0.081 & $0.061-0.11$ \\
\hline $\mathrm{Fe}$ & 2.5 & 1.4 & $0 \cdot 87-2 \cdot 6$ & $1 \cdot 3$ & 0.89 & $0.60-1.85$ & 1.9 & $1 \cdot 6$ & $1 \cdot 2-2 \cdot 2$ \\
\hline $\mathrm{Zn}$ & 16 & 15 & $9 \cdot 2-20$ & 17 & 16 & $11-22$ & 16 & 16 & $11-20$ \\
\hline $\mathrm{Se}$ & 0.43 & 0.41 & $0.32-0.53$ & 0.39 & 0.40 & $0.33-0.48$ & 0.41 & 0.39 & $0.33-0.48$ \\
\hline
\end{tabular}

${ }^{*}$ Percentage of samples $>$ limits of quantification for $\mathrm{Cr}, \mathrm{Mn}, \mathrm{Fe}, \mathrm{Zn}$ and Se was 99.6, 99.8, 100, 100 and 100, respectively.

in spot samples during the study period. Mixed random-effect models were utilised to estimate the between-individual, within-individual inter-day and within-individual intra-day variances in spot samples. For the first-morning and 24-h specimens, only the between-individual and within-individual variances were estimated. The variance apportionment of these elements was further separately reported for samples that were collected days apart (on days 0, 1, 2, 3 and 4) and months apart (on days 0, 30, 60 and 90). In addition, a stratified analysis was conducted to compare the variance apportionment for samples collected in the morning (0.00-11.59 hours), afternoon (12.0018.00 hours) and evening (18.01-23.59 hours) ${ }^{(30)}$. ICC, the proportion of between-individual variance and the total variance, was used to identify the degree of reproducibility. An ICC value $<0.40$ is regarded as poor reproducibility, $0.40-0.75$ as fair to good reproducibility and $\geq 0.75$ as excellent reproducibility ${ }^{(31)}$.

Mixed regression models were constructed to evaluate how well spot or first-morning specimens predicted the same-day 24-h collections. The predictive ability of the models was evaluated using coefficients of determination $\left(R^{2}\right)$. Marginal $R^{2}$ and conditional $R^{2}$ were separately computed to characterise the proportion of variance explained by fixed or random effects ${ }^{(32)}$.

To evaluate how well single or repeated randomly selected specimens identified the highest tertile (top 33\%) of 3-month average exposures ${ }^{(33)}$, the arithmetic mean of log-transformed $\mathrm{Cr}, \mathrm{Mn}, \mathrm{Fe}, \mathrm{Zn}$ and Se concentrations were computed for each participant using all their spot samples gathered over 3 months; the men who were truly in the highest (top $33 \%$ ) exposure group were then identified. Afterwards, ten data sets were created, and each containing a single randomly selected spot sample (or firstmorning void) from each participant; the 'predicted' highest (top $33 \%$ ) exposure group was also identified. The average sensitivity and specificity across ten separate data sets were reported. The analyses were replicated to evaluate whether collecting repeated specimens (two or three) from each participant improved the classification.

\section{Statistical power}

The sample size of this study was estimated using the $\mathrm{R}$ 'ICC.Sample. Size-package' based on the method developed by Zou ${ }^{(34)}$. Assuming that the ICC of creatinine-adjusted $\mathrm{Cr}$, $\mathrm{Mn}, \mathrm{Fe}, \mathrm{Zn}$ and Se were higher than $0 \cdot 15$, according to previously published data $^{(17,22)}, 461$ measurements would be sufficient to achieve a power of $90 \%$ for our reliability analysis.

\section{Results}

Table 1 presents the unadjusted $(\mu \mathrm{g} / \mathrm{l})$, creatinine-adjusted $(\mu \mathrm{g} / \mathrm{g}$ creatinine) and UER ( $\mu \mathrm{g} / \mathrm{h})$ of urinary $\mathrm{Cr}, \mathrm{Mn}, \mathrm{Fe}, \mathrm{Zn}$ and Se in three different sample types. Detection rates of $\mathrm{Cr}, \mathrm{Mn}, \mathrm{Fe}, \mathrm{Zn}$ and Se in spot samples were 99.6\%, 99.8\%, $100 \%, 100 \%$ and $100 \%$, respectively. Line chart showed that creatinine-adjusted concentrations of $\mathrm{Cr}, \mathrm{Mn}, \mathrm{Fe}$, Se and $\mathrm{Zn}$ changed up to two or three orders of magnitude (online Supplementary Fig. S1). However, no apparent rhythmic pattern was observed.

Table 2 shows the variance apportionment of $\mathrm{Cr}, \mathrm{Mn}, \mathrm{Fe}, \mathrm{Zn}$ and $S e$ in spot samples based on unadjusted, creatinine-adjusted, creatinine as a covariate and UER models. The lowest Akaike information criterion value was achieved with creatinineadjusted models for $\mathrm{Zn}$, creatinine as a covariate model and UER model for Se. However, the between-individual and within-individual variance components of these elements were similar based on different correction models. Given that modelling creatinine as a covariate cannot be implemented for 24-h collections and that the UER model is not practical for large population studies since sampling volume and time are required for 
Table 2. Variance apportionment of log-transformed concentrations of chromium, manganese, iron, zinc and selenium in spot samples collected from eleven men $(n 529)$

(Akaike information criteria (AIC); variances $\left(\sigma^{2}\right)$ and percentages)

\begin{tabular}{|c|c|c|c|c|c|c|c|c|c|c|}
\hline \multirow[b]{2}{*}{ Models } & \multicolumn{2}{|c|}{$\mathrm{Cr}$} & \multicolumn{2}{|c|}{$\mathrm{Mn}$} & \multicolumn{2}{|c|}{$\mathrm{Fe}$} & \multicolumn{2}{|c|}{$\mathrm{Zn}$} & \multicolumn{2}{|c|}{$\mathrm{Se}$} \\
\hline & $\sigma^{2}$ & $\%$ & $\sigma^{2}$ & $\%$ & $\sigma^{2}$ & $\%$ & $\sigma^{2}$ & $\%$ & $\sigma^{2}$ & $\%$ \\
\hline \multicolumn{11}{|l|}{ Unadjusted $(\mu \mathrm{g} / \mathrm{l})$} \\
\hline $\mathrm{AIC}^{*}$ & \multicolumn{2}{|c|}{601} & \multicolumn{2}{|c|}{600} & \multicolumn{2}{|c|}{511} & \multicolumn{2}{|c|}{620} & \multicolumn{2}{|c|}{561} \\
\hline Between-individual $\sigma^{2} \dagger$ & 0.001 & 1 & 0.001 & 1 & 0.007 & 4 & 0.058 & 24 & 0.022 & 12 \\
\hline Within-individual, inter-day $\sigma^{2} \ddagger$ & 0.068 & 32 & 0.033 & 17 & 0.018 & 11 & 0.032 & 13 & 0.026 & 13 \\
\hline Within-individual, intra-day $\sigma^{2} \S$ & 0.143 & 67 & 0.155 & 82 & 0.134 & 85 & 0.155 & 63 & 0.143 & 75 \\
\hline \multicolumn{11}{|l|}{ Creatinine-adjusted ( $\mu \mathrm{g} / \mathrm{g}$ creatinine) } \\
\hline $\mathrm{AIC}^{\star}$ & \multicolumn{2}{|c|}{701} & \multicolumn{2}{|c|}{875} & \multicolumn{2}{|c|}{765} & \multicolumn{2}{|c|}{93} & \multicolumn{2}{|c|}{492} \\
\hline Between-individual $\sigma^{2} \dagger$ & 0.001 & 1 & 0.023 & 7 & 0.021 & 8 & 0.052 & 41 & 0.001 & 3 \\
\hline Within-individual, inter-day $\sigma^{2} \ddagger$ & 0.049 & 21 & 0.015 & 5 & 0.006 & 2 & 0.021 & 17 & 0.017 & 50 \\
\hline Within-individual, intra-day $\sigma^{2} \S$ & 0.185 & 78 & 0.278 & 88 & 0.231 & 90 & 0.053 & 42 & 0.016 & 47 \\
\hline \multicolumn{11}{|l|}{ Creatinine modelled as a covariate } \\
\hline $\mathrm{AIC}^{*}$ & \multicolumn{2}{|c|}{579} & \multicolumn{2}{|c|}{606} & \multicolumn{2}{|c|}{510} & \multicolumn{2}{|c|}{156} & \multicolumn{2}{|c|}{150} \\
\hline Between-individual $\sigma^{2} \dagger$ & 0.001 & 1 & 0.001 & 1 & 0.007 & 5 & 0.050 & 38 & 0.002 & 4 \\
\hline Within-individual, inter-day $\sigma^{2} \ddagger$ & 0.061 & 31 & 0.033 & 17 & 0.016 & 10 & 0.021 & 16 & 0.018 & 34 \\
\hline Within-individual, intra-day $\sigma^{2} \S$ & 0.137 & 68 & 0.155 & 82 & 0.133 & 85 & 0.060 & 46 & 0.033 & 62 \\
\hline \multicolumn{11}{|l|}{ Urinary excretion rate $(\mu \mathrm{g} / \mathrm{h})$} \\
\hline $\mathrm{AIC}^{\star}$ & \multicolumn{2}{|c|}{799} & \multicolumn{2}{|c|}{966} & \multicolumn{2}{|c|}{878} & \multicolumn{2}{|c|}{328} & \multicolumn{2}{|c|}{85} \\
\hline Between-individual $\sigma^{2} \dagger$ & 0.003 & 1 & 0.016 & 4 & 0.017 & 5 & 0.063 & 38 & 0.014 & 17 \\
\hline Within-individual, inter-day $\sigma^{2} \ddagger$ & 0.043 & 16 & 0.006 & 2 & 0.001 & 1 & 0.013 & 8 & 0.015 & 18 \\
\hline Within-individual, intra-day $\sigma^{2} \S$ & 0.228 & 83 & 0.342 & 94 & 0.293 & 94 & 0.091 & 54 & 0.055 & 65 \\
\hline
\end{tabular}

${ }^{*} \mathrm{AIC}$ values were used to compare the model fits.

$\dagger$ Proportion of between-person variance to total variance.

¥ Proportion of within-person inter-day variance to total variance.

$\S$ Proportion of within-person intra-day variance to total variance.

calculation, only creatinine-adjusted concentrations were used for all consequent analyses.

Table 3 shows the variance apportionment of creatinineadjusted $\mathrm{Cr}, \mathrm{Mn}, \mathrm{Fe}, \mathrm{Zn}$ and Se concentrations in three different sample types. Fair to good reproducibility was obtained for serial measurements of $\mathrm{Zn}$ (creatinine-adjusted ICC $=0.41$ ) in spot samples over 3 months, whereas $\mathrm{Cr}, \mathrm{Mn}$, Fe and Se showed poor reproducibility (creatinine-adjusted $\mathrm{ICC}=0 \cdot 01-0 \cdot 08$ ). For $\mathrm{Cr}$, $\mathrm{Mn}, \mathrm{Fe}$ and $\mathrm{Zn}$, the within-individual intra-day variance was the largest component of the total variance (range: 42-90\%). For Se, however, the within-individual inter-day variance was predominant $(50 \%)$. Compared with spot samples, apparent increases in ICC were obtained for $\mathrm{Mn}$ and Fe in first-morning voids, and $\mathrm{Mn}, \mathrm{Fe}$ and $\mathrm{Zn}$ in 24-h collections. However, the within-individual variance remained larger than the betweenindividual variance, except for $\mathrm{Zn}$ in 24-h collection. The results were largely unchanged when additionally including 'time interval since the prior urination' as a covariate ( $n$ 529; data not shown).

Stratified analyses showed that the reproducibility of serial measurements of $\mathrm{Zn}$ in spot samples collected days apart was fair to good (creatinine-adjusted ICC $=0.47$ ), which became poor when the samples were gathered months apart (creatinineadjusted ICC $=0.33$ ). Poor reproducibility ranging from 0.01 to $0 \cdot 12$ was observed for $\mathrm{Cr}, \mathrm{Mn}, \mathrm{Fe}$ and Se, irrespective of whether the spot samples were gathered days apart or months apart. Compared with spot samples, apparently higher ICC $(>0 \cdot 20)$ was obtained for $\mathrm{Mn}, \mathrm{Fe}$ and $\mathrm{Zn}$ in first-morning and 24-h specimens gathered days apart, and $\mathrm{Mn}$ and $\mathrm{Fe}$ in first-morning and 24-h specimens gathered months apart (Table 3). The variance apportionment of $\mathrm{Cr}, \mathrm{Mn}, \mathrm{Fe}, \mathrm{Zn}$ and $\mathrm{Se}$ in the samples collected at different times of the day was also estimated. The reproducibility of $\mathrm{Cr}, \mathrm{Mn}, \mathrm{Fe}$ and Se was poor irrespective of whether the samples were collected in the morning, afternoon or evening ( $\mathrm{ICC}=0 \cdot 01-0 \cdot 13$ ). Fair to good reproducibility was observed for $\mathrm{Zn}$ in the afternoon and evening samples (ICC $=0.55$ and 0.48 , respectively) (online Supplementary Table S1).

Table 4 shows how well spot or first-morning specimens predicate the same-day 24-h collections. Low to moderate predictive power was achieved for $\mathrm{Cr}, \mathrm{Mn}, \mathrm{Fe}, \mathrm{Zn}$ and Se based on spot samples (conditional $R^{2}: 0 \cdot 27-0 \cdot 65$ ). Compared with spot samples, using first-morning voids as predictors provided apparent increases in conditional $R^{2}$ for $\mathrm{Cr}(0.73 v .0 .27)$ and slight increases for $\operatorname{Zn}(0.81 v .0 .65)$ and Se (0.75 v. 0.59).

Table 5 shows the results of sensitivity and specificity analyses. When single spot sample or first-morning void was used to identify the highest tertile of 3-month average concentrations, relatively low sensitivities in a range of $0 \cdot 23-0 \cdot 50$ were observed for $\mathrm{Cr}, \mathrm{Mn}, \mathrm{Fe}, \mathrm{Zn}$ and Se. Compared with a single measurement in spot samples, $\geq 10 \%$ increases in sensitivities were observed for all five elements when two or three spot samples were randomly selected from each men days apart. However, moderate sensitivity was obtained only for Zn (0.67). Similarly, using two or three first-morning voids as predictors showed higher sensitivity for $\mathrm{Cr}, \mathrm{Mn}, \mathrm{Fe}, \mathrm{Zn}$ and Se compared with a single first-morning void. Collection of specimens months apart did not offer an apparent improvement in exposure classification over the specimens collected days apart.

\section{Discussion}

Among eleven non-occupationally exposed healthy adult men, high within-individual variability in the concentrations of $\mathrm{Cr}, \mathrm{Mn}$, 
Table 3. Variance of log-transformed creatinine-adjusted chromium, manganese, iron, zinc and selenium concentrations in three sample types* (Intraclass correlation coefficients (ICC); variances $\left(\sigma^{2}\right)$ and percentages)

\begin{tabular}{|c|c|c|c|c|c|c|c|c|c|c|}
\hline \multirow[b]{2}{*}{ Type of samples } & \multicolumn{2}{|c|}{$\mathrm{Cr}$} & \multicolumn{2}{|c|}{$\mathrm{Mn}$} & \multicolumn{2}{|c|}{$\mathrm{Fe}$} & \multicolumn{2}{|c|}{$\mathrm{Zn}$} & \multicolumn{2}{|c|}{ Se } \\
\hline & $\sigma^{2}$ & $\%$ & $\sigma^{2}$ & $\%$ & $\sigma^{2}$ & $\%$ & $\sigma^{2}$ & $\%$ & $\sigma^{2}$ & $\%$ \\
\hline \multicolumn{11}{|c|}{$\begin{array}{l}\text { Samples collected during a 3-month period } \\
\text { Spot samples ( } n \text { 529) }\end{array}$} \\
\hline $\begin{array}{l}\text { Spot samples ( } n \text { 529) } \\
\text { ICC }\end{array}$ & \multicolumn{2}{|c|}{0.01} & \multicolumn{2}{|c|}{0.07} & \multicolumn{2}{|c|}{0.08} & \multicolumn{2}{|c|}{0.41} & \multicolumn{2}{|c|}{0.03} \\
\hline Between-individual $\sigma^{2} \dagger$ & 0.001 & 1 & 0.022 & 7 & 0.021 & 8 & 0.052 & 41 & 0.001 & 3 \\
\hline Within-individual, inter-day $\sigma^{2} \ddagger$ & 0.048 & 20 & 0.015 & 5 & 0.006 & 2 & 0.021 & 17 & 0.017 & 50 \\
\hline Within-individual, intra-day $\sigma^{2} \S$ & 0.185 & 79 & 0.278 & 88 & 0.231 & 90 & 0.053 & 42 & 0.016 & 47 \\
\hline \multicolumn{11}{|l|}{ First-morning voids ( $n$ 88) } \\
\hline ICC & \multicolumn{2}{|c|}{0.06} & \multicolumn{2}{|c|}{0.37} & \multicolumn{2}{|c|}{0.41} & \multicolumn{2}{|c|}{0.44} & \multicolumn{2}{|c|}{0.07} \\
\hline Between-individual $\sigma^{2} \dagger$ & 0.021 & 6 & 0.063 & 37 & 0.060 & 41 & 0.049 & 44 & 0.002 & 7 \\
\hline Within-individual $\sigma^{2} \ddagger$ & 0.356 & 94 & 0.109 & 63 & 0.086 & 59 & 0.063 & 56 & 0.026 & 93 \\
\hline \multicolumn{11}{|l|}{ 24-h collections ( $n$ 88) } \\
\hline ICC & \multicolumn{2}{|c|}{0.01} & \multicolumn{2}{|c|}{0.27} & \multicolumn{2}{|c|}{0.32} & & & & \\
\hline Between-individual $\sigma^{2} \dagger$ & 0.001 & 1 & 0.037 & 27 & 0.032 & 32 & 0.045 & 57 & 0.001 & 5 \\
\hline Within-individual $\sigma^{2} \ddagger$ & 0.202 & 99 & 0.099 & 73 & 0.068 & 68 & 0.034 & 43 & 0.020 & 95 \\
\hline Samples collected days apart & & & & & & & & & & \\
\hline Spot sample (n 326) & & & & & & & & & & \\
\hline ICC & & & & & & & & & & \\
\hline Between-individual $\sigma^{2} \dagger$ & 0.001 & 1 & 0.026 & 9 & 0.014 & 6 & 0.060 & 47 & 0.003 & 12 \\
\hline Within-individual, inter-day $\sigma^{2} \ddagger$ & 0.031 & 20 & 0.013 & 4 & 0.003 & 1 & 0.010 & 8 & 0.010 & 40 \\
\hline Within-individual, intra-day $\sigma^{2} \S$ & 0.123 & 79 & 0.262 & 87 & 0.207 & 93 & 0.058 & 45 & 0.012 & 48 \\
\hline First-morning voids ( $n$ 55) & & & & & & & & & & \\
\hline ICC & & & & & & & & & & \\
\hline Between-individual $\sigma^{2} \dagger$ & 0.023 & 18 & 0.051 & 35 & 0.046 & 32 & 0.084 & 71 & 0.004 & 16 \\
\hline Within-individual $\sigma^{2} \ddagger$ & 0.105 & 82 & 0.095 & 65 & $0 \cdot 100$ & 68 & 0.035 & 29 & 0.021 & 84 \\
\hline 24-h collections ( $n$ 55) & & & & & & & & & & \\
\hline ICC & & & & & & & & & & \\
\hline Between-individual $\sigma^{2} \dagger$ & 0.001 & 1 & 0.042 & 30 & 0.022 & 29 & 0.058 & 74 & 0.003 & 20 \\
\hline Within-individual $\sigma^{2} \ddagger$ & 0.075 & 99 & 0.096 & 70 & 0.053 & 71 & 0.020 & 26 & 0.012 & 80 \\
\hline Samples collected months apart & & & & & & & & & & \\
\hline Spot sample $(n$ 265) & & & & & & & & & & \\
\hline ICC & & & & & & & & & & \\
\hline Between-individual $\sigma^{2} \dagger$ & 0.001 & 1 & 0.027 & 9 & 0.026 & 9 & 0.039 & 33 & 0.001 & 1 \\
\hline Within-individual, inter-day $\sigma^{2} \ddagger$ & 0.072 & 23 & 0.006 & 2 & 0.003 & 1 & 0.035 & 30 & 0.017 & 43 \\
\hline Within-individual, intra-day $\sigma^{2} \S$ & 0.233 & 76 & 0.274 & 89 & 0.248 & 89 & 0.044 & 37 & 0.022 & 56 \\
\hline First-morning voids ( $n$ 44) & & & & & & & & & & \\
\hline ICC & & & & & & & & & & \\
\hline Between-individual $\sigma^{2} \dagger$ & 0.001 & 1 & 0.071 & 36 & 0.058 & 39 & 0.036 & 33 & 0.001 & 3 \\
\hline Within-individual $\sigma^{2} \ddagger$ & 0.643 & 99 & 0.127 & 64 & 0.092 & 61 & 0.072 & 67 & 0.030 & 97 \\
\hline 24-h collections ( $n$ 44) & & & & & & & & & & \\
\hline ICC & & & & & & & & & & \\
\hline Between-individual $\sigma^{2} \dagger$ & 0.001 & 1 & 0.054 & 43 & 0.052 & 42 & 0.030 & 39 & 0.001 & 4 \\
\hline Within-individual $\sigma^{2} \ddagger$ & 0.327 & 99 & 0.072 & 57 & 0.072 & 58 & 0.047 & 61 & 0.022 & 96 \\
\hline
\end{tabular}

*Days apart: days 0, 1, 2, 3, and 4; months apart: days 0, 30, 60, and 90

† Proportion of between-individual variance to total variance.

$\ddagger$ Proportion of within-individual inter-day variance to total variance.

$\S$ Proportion of within-individual intra-day variance to total variance.

Fe and Se was exhibited in spot samples over periods ranging from days to months (creatinine-adjusted ICC $=0 \cdot 01-0 \cdot 12$ ). The reproducibility of $\mathrm{Zn}$ concentrations in spot samples was fair to good over five consecutive days (creatinine-adjusted ICC $=0.47$ ), which became poor when the specimens were gathered months apart (creatinine-adjusted ICC $=0.33$ ). Similar to the trend of ICC, our classification analysis showed that using one, two or even three spot samples to identify the highest tertile of 3-month average concentrations of $\mathrm{Cr}, \mathrm{Mn}, \mathrm{Fe}$ and Se could result in high degree of classification error (i.e. low sensitivities); by contrast, two and three randomly selected spot samples appeared to offer moderate to high sensitivities ( $\geq 0 \cdot 6$ ) for $\mathrm{Zn}$.

$\mathrm{Cr}, \mathrm{Mn}, \mathrm{Fe}, \mathrm{Zn}$ and Se are proposed to be essential elements that are naturally present in food and water and are also available as dietary supplements ${ }^{(1,35)}$. Additional intake may benefit individuals who have insufficient intake. However, excessive exposures have demonstrated adverse health effects both in animal and in human studies ${ }^{(1,35)}$. In this study, we found high within-individual variability in urinary concentration of $\mathrm{Cr}, \mathrm{Mn}$, $\mathrm{Fe}$ and Se over both short and long periods of time, which is not unexpected, given the changing exposure status due to the variation in the daily dietary consumption ${ }^{(19)}$. The changing urinary flow rate that is related to salt intake and physiological status may also affect the reproducibility of these elements ${ }^{(19)}$. The reproducibility of $\mathrm{Zn}$ concentrations in spot samples was fair to good over five consecutive days (creatinine-adjusted ICC = $0 \cdot 47$ ). Within-individual variation in biomarker concentrations is affected by various factors, especially the elimination half-life. 
Table 4. Creatinine-adjusted models of 24-h concentrations of chromium, manganese, iron, zinc and selenium using the same-day spot samples or firstmorning voids as predictors $\dagger$

( $\beta$-Coefficients, $95 \%$ confidence intervals, intercepts, marginal coefficients of determination $\left(R^{2}\right)$ and conditional $R^{2}$ )

\begin{tabular}{|c|c|c|c|c|c|}
\hline Types of sample & $\beta$ & $95 \% \mathrm{Cl}$ & Intercept & Marginal $R^{2} \S$ & Conditional $R^{2} \|$ \\
\hline \multicolumn{6}{|c|}{ Spot samples ( $n$ 529)‡ } \\
\hline $\mathrm{Cr}$ & $0.48^{*}$ & $0.40,0.55$ & 0.32 & 0.22 & 0.27 \\
\hline $\mathrm{Mn}$ & $0.21^{*}$ & $0.17,0.26$ & 0.28 & 0.12 & 0.37 \\
\hline $\mathrm{Fe}$ & $0.19^{*}$ & $0.15,0.23$ & 1.80 & $0 \cdot 10$ & 0.39 \\
\hline $\mathrm{Zn}$ & $0.38^{*}$ & $0.34,0.43$ & $2 \cdot 20$ & 0.31 & 0.65 \\
\hline $\mathrm{Se}$ & $0.56^{*}$ & $0.52,0.61$ & 0.57 & 0.56 & 0.59 \\
\hline \multicolumn{6}{|c|}{ First-morning voids ( $n 88$ ) } \\
\hline $\mathrm{Cr}$ & $0.63^{*}$ & $0.55,0.71$ & 0.40 & 0.72 & 0.73 \\
\hline $\mathrm{Mn}$ & $0.38^{*}$ & $0.20,0.56$ & 0.33 & 0.18 & 0.31 \\
\hline $\mathrm{Fe}$ & $0.28^{*}$ & $0.10,0.45$ & 1.67 & 0.12 & 0.30 \\
\hline $\mathrm{Zn}$ & $0.63^{*}$ & $0.54,0.72$ & 1.26 & 0.69 & $0 \cdot 81$ \\
\hline Se & $0.75^{*}$ & $0.66,0.84$ & 0.32 & 0.74 & 0.75 \\
\hline
\end{tabular}

${ }^{*} P<0.001$.

† Spot samples and first-morning voids were analysed on a log-transformed scale.

$\ddagger$ Spot samples included first-morning voids.

$\S$ Proportion of variance explained by fixed effects.

II Amount of variance explained by fixed and random effects.

Table 5. Sensitivity and specificity of one, two or three urine samples as a predictor to identify the highly exposed men (top $33 \%$ ) based on their 3-month average measures*

\begin{tabular}{|c|c|c|c|c|c|c|c|c|c|c|}
\hline \multirow[b]{2}{*}{ Type of samples } & \multicolumn{2}{|c|}{$\mathrm{Cr}$} & \multicolumn{2}{|c|}{$\mathrm{Mn}$} & \multicolumn{2}{|c|}{$\mathrm{Fe}$} & \multicolumn{2}{|c|}{$\mathrm{Zn}$} & \multicolumn{2}{|c|}{$\mathrm{Se}$} \\
\hline & Sensitivity & Specificity & Sensitivity & Specificity & Sensitivity & Specificity & Sensitivity & Specificity & Sensitivity & Specificity \\
\hline \multicolumn{11}{|l|}{ Spot samples } \\
\hline One sample & 0.27 & 0.73 & 0.33 & 0.75 & 0.37 & 0.76 & 0.43 & 0.79 & 0.37 & 0.76 \\
\hline $\begin{array}{l}\text { Two samplest } \\
\text { (days apart) }\end{array}$ & 0.40 & $0 \cdot 78$ & 0.37 & 0.76 & 0.43 & 0.79 & 0.60 & 0.85 & 0.47 & 0.80 \\
\hline $\begin{array}{l}\text { Two samples } \dagger \\
\text { (months apart) }\end{array}$ & 0.27 & 0.73 & 0.33 & 0.75 & 0.33 & 0.75 & 0.60 & 0.85 & 0.43 & 0.79 \\
\hline $\begin{array}{l}\text { Three samplest } \\
\text { (days apart) }\end{array}$ & 0.37 & $0 \cdot 76$ & 0.47 & $0 \cdot 80$ & 0.47 & 0.80 & 0.67 & 0.88 & 0.47 & 0.80 \\
\hline $\begin{array}{r}\text { Three samplest } \\
\text { (months apart) }\end{array}$ & 0.40 & 0.78 & 0.33 & 0.75 & 0.40 & $0 \cdot 78$ & 0.73 & 0.90 & 0.63 & 0.86 \\
\hline \multicolumn{11}{|l|}{ First-morning voids } \\
\hline One sample & 0.40 & 0.78 & 0.23 & 0.71 & 0.37 & 0.76 & 0.50 & 0.81 & 0.37 & 0.76 \\
\hline $\begin{array}{c}\text { Two samplest } \\
\text { (days apart) }\end{array}$ & 0.43 & $0 \cdot 79$ & 0.40 & 0.78 & 0.50 & 0.81 & 0.57 & 0.84 & 0.37 & 0.76 \\
\hline $\begin{array}{l}\text { Two samplest } \\
\text { (months apart) }\end{array}$ & 0.37 & $0 \cdot 76$ & 0.37 & $0 \cdot 76$ & 0.47 & 0.80 & 0.57 & 0.84 & 0.40 & 0.78 \\
\hline $\begin{array}{l}\text { Three samplest } \\
\text { (days apart) }\end{array}$ & 0.53 & $0 \cdot 83$ & 0.47 & $0 \cdot 80$ & 0.37 & $0 \cdot 76$ & $0 \cdot 70$ & 0.89 & 0.50 & 0.81 \\
\hline $\begin{array}{r}\text { Three samplest } \\
\text { (months apart) }\end{array}$ & 0.63 & $0 \cdot 86$ & 0.43 & 0.79 & 0.43 & 0.79 & 0.53 & $0 \cdot 80$ & 0.30 & 0.74 \\
\hline
\end{tabular}

*Days apart: days $0,1,2,3$, and 4; months apart: days $0,30,60$, and 90 . Calculations use creatinine-adjusted $\mathrm{Cr}$, Mn, Fe, $\mathrm{Zn}$ and Se concentrations ( $\mu$ g/g creatinine) on a log ${ }_{10}$ scale. † Specimens were collected on different days.

$\mathrm{Zn}$ is mainly stored in muscle and bones with a half-life of 244 $\mathrm{d}^{(36-38)}$, which is longer than that of $\mathrm{Cr}, \mathrm{Mn}, \mathrm{Fe}$ and Se (range from $<30 \mathrm{~h}$ to $<116 \mathrm{~d})^{(39-41)}$. Consistent with our findings, previous studies have conformably revealed that the withinindividual variance exceeds the between-individual variance for urinary concentration of $\mathrm{Cr}, \mathrm{Mn}, \mathrm{Zn}$ and $\mathrm{Se}^{(17,22)}$, though the reported ICC vary slightly across studies, probably because of the differences in study design (e.g. study population, sample types and sampling duration). For instance, Paglia et al. ${ }^{(22)}$ reported a poor reproducibility for $\mathrm{Zn}$ in first-morning voids across seasons (creatinine-adjusted ICC $=0 \cdot 37$ ), which was comparable to our first-morning voids that were collected months apart (creatinine-adjusted ICC $=0.33$ ) but was much lower than our samples that were collected days apart (creatinine-adjusted ICC $=0.71$ ).

Making collections over $24 \mathrm{~h}$ is proposed as the 'gold standard' to evaluate an individuals' daily exposures to chemicals that are excreted mainly through urine ${ }^{(42)}$. In the present study, only low to moderate predictive ability (conditional $R^{2}$ $0 \cdot 27-0 \cdot 65$ ) was obtained when using spot samples as predictors of the same-day 24-h concentrations of $\mathrm{Cr}, \mathrm{Mn}, \mathrm{Fe}, \mathrm{Zn}$ and Se. A first-morning void is recommended as a better sample type than spot sample since it is more concentrated and reflects accumulative exposures ${ }^{(33,43)}$. However, compared with spot samples, using first-morning voids to predict the same-day 24-h average exposures showed an apparent advantage only for $\mathrm{Cr}$ 
(conditional $R^{2}: 0 \cdot 73 v \cdot 0 \cdot 27$ ). Moreover, although serial measurements of $\mathrm{Mn}$, Fe and $\mathrm{Zn}$ in first-morning voids or 24-h collections showed higher reproducibility than spot samples, their withinindividual variance remained larger than the between-individual variance, suggesting that improvements in exposure estimation over weeks or months cannot offset the additional effort needed to gather these two sample types. In support of this speculation, our classification analysis revealed that a single measurement of $\mathrm{Cr}, \mathrm{Mn}, \mathrm{Fe}, \mathrm{Zn}$ and Se in first-morning voids only correctly identified $\leq 50 \%$ of the men who truly had high (top 33\%) 3-month average exposures.

Our findings highlight the importance of characterising analyte-specific patterns of variability to improve exposure estimation in epidemiological studies. In our classification analysis, we revealed a tendency similar to that of the ICC. For instance, two spot samples are sufficient to correctly classify $60 \%$ of the men who had the highest (top $33 \%$ ) 3-month average $\mathrm{Zn}$ concentrations; for $\mathrm{Cr}, \mathrm{Mn}$, Fe and Se, however, at least three specimens were required to achieve a similar sensitivity. In our stratified analyses, we compared the variance apportionment for samples that were collected at different time points and found that the sensitivity and specificity of specimens collected months apart did not offer apparent improvements in exposure classification over the specimens collected days apart. The reproducibility of $\mathrm{Cr}, \mathrm{Mn}, \mathrm{Fe}$ and Se was uniformly poor irrespective of whether the samples were collected in the morning, afternoon or evening, which indicates that changing the collection time of day will not substantially improve the exposure estimation. For $\mathrm{Zn}$, however, specimens collected in the afternoon and evening showed slightly higher reproducibility than that the morning samples, which means changing the collection time of day will optimise exposure assessment when multiple specimens are collected over a period of time.

The geometric mean concentrations of $\mathrm{Cr}, \mathrm{Mn}, \mathrm{Fe}, \mathrm{Zn}$ and $\mathrm{Se}$ in this study were comparable with those reported among 2004 adult residents of Wuhan, China ${ }^{(25)}$. However, our geometric mean urinary concentrations of $\mathrm{Mn}(1.5 \mu \mathrm{g} / \mathrm{l})$ and Se $(7.5 \mu \mathrm{g} / \mathrm{l})$ were different from those reported for the males from the CHMS of Canada $(0.078 \mu \mathrm{g} / \mathrm{l} \text { and } 57 \mu \mathrm{g} / \mathrm{l} \text { for } \mathrm{Mn} \text { and Se, respectively })^{(14)}$ and adults from Germany $(0.063 \mu \mathrm{g} / \mathrm{l} \text { for } \mathrm{Mn})^{(44)}$, implying regional variability in the extent and source of exposure. The main strength of this study was that we comprehensively assessed the within-day, between-day and between-month variability in $\mathrm{Cr}$, $\mathrm{Mn}, \mathrm{Fe}, \mathrm{Zn}$ and Se concentrations in spot, first-morning and 24-h urine specimens. The impact of different concentration correction methods (i.e. creatinine-adjusted, creatinine as a covariate and UER models) on the reproducibility of these elements was also assessed. Our findings support the feasibility of using the creatinine-adjusted model to control for urinary dilution for Cr, Mn, Fe, Zn and Se in healthy adult men. Nevertheless, our study has several limitations. First, our recruited study volunteers were relatively homogeneous (young men aged between 21 and 28 years), living in a restricted district during the study period, which may have resulted in an underestimation of the between-individual variability compared with the general population who have more heterogeneous demographic characteristics (e.g. sex, and age). Second, our study population was relatively small, which limits our ability to explore the effects of various sources of uncertainties (e.g. exposure uncertainties that were related to diet and lifestyle) on the within-individual and between-individual variances. Third, duplicate aliquots were not carried out to evaluate uncertainty due to analytical factors, which may have also biased our estimation of ICC.

In conclusion, our findings revealed that serial measurements of $\mathrm{Cr}, \mathrm{Mn}, \mathrm{Fe}, \mathrm{Zn}$ and Se in spot samples, first-morning voids and 24-h collections uniformly showed strong withinindividual variability, and a single measurement is not enough to efficiently characterise individuals' long-term exposures. Collection of repeated specimens is a feasible approach to reduce exposure misclassification. If multiple specimens were collected from each individual over a period of time, changing the collection time of day may optimise exposure assessment for $\mathrm{Zn}$; whereas this may not be necessary for $\mathrm{Cr}, \mathrm{Mn}, \mathrm{Fe}$ and $\mathrm{Se}$.

\section{Supplementary material}

For supplementary material/s referred to in this article, please visit https://doi.org/10.1017/S0007114519001193

\section{Acknowledgements}

The authors thank all the individuals who volunteered to participate in this study as well as those who gave the technical assistance.

The project was supported by the National Key Research and Development Program of China (2017YFC0907500 and 2017YFC0907504), Hubei Province Science Fund for Distinguished Young Scholars (2018CFA033) and the National Postdoctoral Program for Innovative Talents (No. BX201700087). None of the funding sponsors was involved in the design and conduct of the study; collection, management, analysis and interpretation of the data; and preparation, review or approval of the manuscript.

H. G. C. performed the statistical analysis, contributed to the discussion, wrote the manuscript, and reviewed and edited the manuscript; Y. J. C, C. C., Z. Z. T., Q. L., P. W., J. X. C. and Y. X. W. collected the data and conducted laboratory analyses; Y. X. W. and A. P. planned and designed the study; H. G. C., Y. X. W. and A. P. have full access to the data in this study and take complete responsibility for the integrity of the data and the accuracy of the data analysis; and all authors contributed to the research conception and design or interpretation and analysis of the data, and drafted, read and approved the final manuscript.

The authors declare that there are no conflicts of interest.

\section{References}

1. National Institutes of Health Office of Dietary Supplements (2018) Dietary supplement fact sheets. https://ods.od.nih. gov/factsheets/list-all/ (accessed November 2018).

2. Mohammadifard N, Humphries KH, Gotay C, et al. (2017) Trace minerals intake: risks and benefits for cardiovascular health. Crit Rev Food Sci Nutr 59, 1-13.

3. Chu A, Foster M \& Samman S (2016) Zinc status and risk of cardiovascular diseases and type 2 diabetes mellitus-a systematic review of prospective cohort studies. Nutrients 8, 707 . 
4. Shan Z, Chen S, Sun T, et al. (2016) U-shaped association between plasma manganese levels and type 2 diabetes. Environ Health Perspect 124, 1876-1881.

5. Himoto T \& Masaki T (2018) Associations between zinc deficiency and metabolic abnormalities in patients with chronic liver disease. Nutrients 10, 88.

6. Yuan Z, Xu X, Ye H, et al. (2015) High levels of plasma selenium are associated with metabolic syndrome and elevated fasting plasma glucose in a Chinese population: a case-control study. J Trace Elem Med Biol 32, 189-194.

7. Shil K \& Pal S (2018) Metabolic adaptability in hexavalent chromium-treated renal tissue: an in vivo study. Clin Kidney J 11, 222-229.

8. Fang S, Zhuo Z, Yu X, et al. (2018) Oral administration of liquid iron preparation containing excess iron induces intestine and liver injury, impairs intestinal barrier function and alters the gut microbiota in rats. J Trace Elem Med Biol 47, $12-20$.

9. Kok FJ, Van Duijn CM, Hofman A, et al. (1988) Serum copper and zinc and the risk of death from cancer and cardiovascular disease. Am J Epidemiol 128, 352-359.

10. Vincent JB (2001) The bioinorganic chemistry of chromium(III). Polybedron 20, 1-26.

11. European Food Safety Authority (2014) Scientific opinion on dietary reference values for chromium1. EFSA J 12, 4185-4185.

12. Esteban M \& Castano A (2009) Non-invasive matrices in human biomonitoring: a review. Environ Int 35, 438-449.

13. Sun Q, Bertrand KA, Franke AA, et al. (2017) Reproducibility of urinary biomarkers in multiple 24-h urine samples. Am J Clin Nutr 105, 159-168.

14. Health Canada (2013) Second report on human biomonitoring of environmental chemicals in Canada. http://www. healthyenvironmentforkids.ca/sites/healthyenvironmentforkids. $\mathrm{ca} /$ files/HumanBiomonitoringReport_EN.pdf_accessed November 2018)

15. Wiesmuller GA, Eckard R, Dobler L, et al. (2007) The environmental specimen bank for human tissues as part of the German Environmental Specimen Bank. Int J Hyg Environ Health 210, 299-305.

16. Fréry N, Saoudi A, Garnier R, et al. (2011) Exposition de la population française aux substances chimiques de l'environnement. Tome 1 (Exposure of the French population to chemical substances in the environment. Vol. 1). Toxicol Anal Clin 29, 441-482.

17. Smolders R, Koch HM, Moos RK, et al. (2014) Inter- and intra-individual variation in urinary biomarker concentrations over a 6-day sampling period. Part 1: metals. Toxicol Lett 231, 249-260

18. Wang YX, Feng W, Zeng Q, et al. (2016) Variability of metal levels in spot, first morning, and 24-hour urine samples over a 3-month period in healthy adult Chinese men. Environ Health Perspect 124, 468-476.

19. Aylward LL, Hays SM, Smolders R, et al. (2014) Sources of variability in biomarker concentrations.J Toxicol Environ Health B Crit Rev 17, 45-61.

20. Barr DB, Wilder LC, Caudill SP, et al. (2005) Urinary creatinine concentrations in the U.S. population: implications for urinary biologic monitoring measurements. Environ Health Perspect 113, 192-200.

21. Gargas ML, Norton RL, Paustenbach DJ, et al. (1994) Urinary excretion of chromium by humans following ingestion of chromium picolinate. Implications for biomonitoring. Drug Metab Dispos 22, 522-529.

22. Paglia G, Miedico O, Tarallo M, et al. (2016) Evaluation of seasonal variability of toxic and essential elements in urine analyzed by inductively coupled plasma mass spectrometry. Expo Health 9, 79-88.

23. Wang YX, Zeng Q, Wang L, et al. (2014) Temporal variability in urinary levels of drinking water disinfection byproducts dichloroacetic acid and trichloroacetic acid among men. Environ Res 135, 126-132.

24. Gibson RS, Gibson IL \& Kitching J (1985) A study of inter- and intrasubject variability in seven-day weighed dietary intakes with particular emphasis on trace elements. Biol Trace Elem Res 8, 79-91.

25. Feng W, He X, Chen M, et al. (2015) Urinary metals and heart rate variability: a cross-sectional study of urban adults in Wuhan, China. Environ Health Perspect 123, 217-222.

26. Wan ZZ, Chen HG, Lu WQ, et al. (2019) Metal/metalloid levels in urine and seminal plasma in relation to computeraided sperm analysis motion parameters. Chemosphere $\mathbf{2 1 4}$, 791-800.

27. Wang YX, Sun Y, Huang Z, et al. (2016) Associations of urinary metal levels with serum hormones, spermatozoa apoptosis and sperm DNA damage in a Chinese population. Environ Int $\mathbf{9 4}$, 177-188.

28. Kim K, Steuerwald AJ, Parsons PJ, et al. (2011) Biomonitoring for exposure to multiple trace elements via analysis of urine from participants in the Study of Metals and Assisted Reproductive Technologies (SMART). J Environ Monit 13, 2413-2419.

29. Akerstrom M, Sallsten G, Lundh T, et al. (2013) Associations between urinary excretion of cadmium and proteins in a nonsmoking population: renal toxicity or normal physiology? Environ Health Perspect 121, 187-191.

30. Preau JL Jr., Wong LY, Silva MJ, et al. (2010) Variability over 1 week in the urinary concentrations of metabolites of diethyl phthalate and di(2-ethylhexyl) phthalate among eight adults: an observational study. Environ Health Perspect 118, 1748-1754.

31. Rosner B (2000) Multisample inference. In Fundamentals of Biostatistics, 5th ed., pp. 511-576. Pacific Grove, CA: Duxbury Press.

32. Nakagawa S \& Schielzeth H (2013) A general and simple method for obtaining $R^{2}$ from generalized linear mixed-effects models. Methods Ecolo Evol 4, 133-142.

33. Bradman A, Kogut K, Eisen EA, et al. (2013) Variability of organophosphorous pesticide metabolite levels in spot and 24-hr urine samples collected from young children during 1 week. Environ Health Perspect 121, 118-124.

34. Zou GY (2012) Sample size formulas for estimating intraclass correlation coefficients with precision and assurance. Stat Med 31, 3972-3981.

35. Sengupta P (2013) Environmental and occupational exposure of metals and their role in male reproductive functions. Drug Chem Toxicol 36, 353-368.

36. Solomons NW (1982) Biological availability of zinc in humans. Am J Clin Nutr 35, 1048-1075.

37. De Roost E, Funck E, Spernol A, et al. (1972) The decay of ${ }^{65} \mathrm{Zn}$. Z Physik 250, 395-412.

38. Chasapis CT, Loutsidou AC, Spiliopoulou CA, et al. (2012) Zinc and human health: an update. Arch Toxicol 86, 521-534.

39. Paustenbach D, Panko J, Fredrick M, et al. (1997) Urinary chromium as a biological marker of environmental exposure: what are the limitations? Regul Toxicol Pharmacol 26, S23-S34.

40. Roels H, Lauwerys R, Genet P, et al. (1987) Relationship between external and internal parameters of exposure to manganese in workers from a manganese oxide and salt producing plant. Am J Ind Med 11, 297-305.

41. Friberg L \& Elinder CG (1993) Biological monitoring of toxic metals. Scand J Work Environ Health 19, Suppl. 1, 7-13. 
42. US Environmental Protection Agency (2014) Code of federal regulations: priority pollutants list. 2014. https://www.gpo. gov/fdsys/pkg/CFR-2014-title40-vol29/xml/CFR-2014-title40vol29-part423-appA.xml (accessed November 2018).

43. Kissel JC, Curl CL, Kedan G, et al. (2005) Comparison of organophosphorus pesticide metabolite levels in single and multiple daily urine samples collected from preschool children in Washington state. J Expo Anal Environ Epidemiol 15, 164-171.

44. Heitland P \& Koster HD (2006) Biomonitoring of 30 trace elements in urine of children and adults by ICP-MS. Clin Chim Acta 365, 310-318. 